\title{
Comprehensive Analysis of Hexagonal Sigma-Delta Modulations for Three-Phase High-Frequency VSC Based on Wide-Bandgap Semiconductors
}

\author{
David Lumbreras, Student Member, IEEE, Jordi Zaragoza, Member, IEEE, Néstor Berbel, Juan Mon, \\ Eduardo Gálvez and Alfonso Collado
}

\begin{abstract}
The efficiency of wide-bandgap (WBG) power converters can be greatly improved using high-frequency modulation techniques. This paper proposes using single-loop and double-loop hexagonal sigma-delta modulation (H- $\Sigma \Delta$ and DH$\Sigma \Delta$ respectively) for voltage source converters (VSC) that use silicon carbide ( $\mathrm{SiC}$ ) semiconductors. These allow high switching frequencies to operate more efficiently than silicon devices. Thus, $\Sigma \Delta$ modulations are excellent candidates for taking advantage of WBG devices. The proposed modulation techniques allow working with a variable switching frequency, thus producing an extreme reduction in switching losses and mitigating the low-order harmonics in comparison with the classical space vector pulse width modulation (SVPWM) technique, and with the innovative variable switching frequency pulse width modulation (VSFPWM). The performance and losses of both $\Sigma \Delta$ techniques are analysed here using Matlab/Simulink and PLECS, and then compared with SVPWM and VSFPWM. Furthermore, the frequency spectrum and the total harmonic distortion (THD) are evaluated. Experimental results performed on a VSC converter that uses SiC MOSFETs show how $\mathrm{H}-\Sigma \Delta$ and $\mathrm{DH}-\Sigma \Delta$ greatly improve efficiency and generate fewer low-order harmonics than the SVPWM and VSFPWM strategies do.
\end{abstract}

Index Terms-Losses, Modulation Techniques, Voltage Source Converter (VSC), PLECS, Wide-bandgap Semiconductors, Sigma-Delta Modulation, Vector Quantization, Power Electronics, Hexagonal Quantizer.

\section{INTRODUCTION}

W IDE-BANDGAP (WBG) semiconductors display material properties that are superior to those of silicon devices. These new materials surpass silicon in every aspect: they can withstand higher voltages and temperatures while working at extremely high switching frequencies [1], [2]. The most mature WBG semiconductors are silicon carbide ( $\mathrm{SiC}$ ) and gallium nitride $(\mathrm{GaN})$, but recent advances have been made through research into other materials [3]. In general, $\mathrm{GaN}$ technology exhibits better features than $\mathrm{SiC}$, but this is currently in its first development stages [4]. Thus, GaN devices are limited to low-voltage applications $(<650 \mathrm{~V})$ while $\mathrm{SiC}$ devices are preferred for high-voltage operations [2]. WBG devices have already been successfully used on several power electronics applications, such as: wireless chargers [5], [6], onboard EV chargers [7], [8], energy storage

D. Lumbreras, J. Zaragoza, N. Berbel, and J. Mon are with the Terrassa Industrial Electronics Group (TIEG), Department of Electronic Engineering, Technical University of Catalonia (UPC), 08222 Terrassa, Spain.

D. Lumbreras, E. Gálvez, and A. Collado are with the R\&D Power Electronics, Circutor S.A., Vial de Sant Jordi, 08232, Viladecavalls (Barcelona), Spain. systems [9], shipboard electrification [10], and AC electric drives [11]. Furthermore, two-level $\mathrm{SiC}$ converters such as voltage source converters (Fig. 1) are becoming the preferred topology in electric vehicles [12]. SiC-based voltage source converters have also been proposed for uninterruptible power supplies [13], and even to connect an aircraft's generator to its electrical grid [14]. Nevertheless, the industry is not fully taking advantage of WBG properties. In order to exploit the capability of switching at high frequencies with minor losses, WBG power converters should use modulation techniques that provide better results at those frequencies, such as through spread spectrum modulations [15].

There are four types of spread-spectrum-based pulse width modulation techniques: random modulations, periodic modulations, programmed modulations, and chaotic modulations [15]. Some works proposed a variable switching frequency pulse width modulation (VSFPWM) as an alternative to the classic spread-spectrum techniques [16], [17]. This technique has been adapted to work with AC drives [18], [19], threelevel converters, and T-type converters [20]. The VSFPWM technique has proved its effectiveness at low switching frequencies. Compared with a space vector pulse width modulation (SVPWM), the VSFPWM reduces the conducted EMIs and the switching losses [16], [17]. However, this technique has not been tested at high frequencies, so its applicability for WBG power converters has not been studied.

Another interesting modulation technique is sigma-delta modulation $(\Sigma \Delta)$, which first appeared in the early 1960s [21], [22]. Nowadays, it is used in audio applications, digital-toanalog converters, sample-rate converters, and digital power amplifiers [23]. The basis of $\Sigma \Delta$ is the following [21]: an analog signal is sampled and compared with the current digital output. The integral of the error is quantized into a digital signal, which is the next output of the modulator. An error

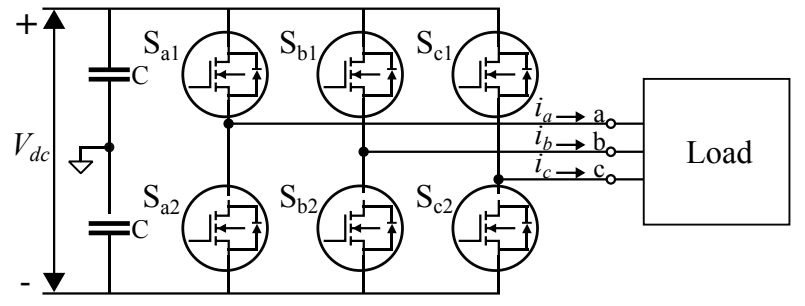

Fig. 1. Voltage source converter with SiC MOSFETs. 
usually occurs between the output signal and the quantifier input, but the resolution is easily improved by oversampling the signal, specifically by sampling the analog input at a frequency higher than the Nyquist frequency [21]-[23]. Other popular methods for improving the resolution of $\Sigma \Delta$ are increasing the integrators, which may destabilize the system [24], and using cascade modulators, which are more complex to implement and limited to low-voltage applications [21], [25].

Power converters are like analog-to-digital converters because they receive analog signals as reference voltages and modulate them by means of discrete switching states [26]. In power electronics, it is usual to sample the signals at the switching frequency, which is much higher than the Nyquist frequency. Hence, applying $\Sigma \Delta$ in power converters guarantees a high oversampling ratio and, therefore, good resolution [26].

Sigma-delta modulation first appeared in power electronics in [27] as an application for resonant power converters. The performance of this technique was studied in [28] for singlephase and three-phase resonant converters. Later, some authors applied $\Sigma \Delta$ to voltage source converters and also studied its frequency spectrum [29], [30]. Luckjiff et al. improved the modulation by using a hexagonal quantizer [26], when they invented and patented hexagonal sigma-delta modulation $(\mathrm{H}-\Sigma \Delta)$ [31]. The same authors analysed the spectrum and switching rate of their new modulation in [32], [33]. Furthermore, these authors studied the effects of the doubleloop hexagonal sigma-delta modulation $(\mathrm{DH}-\Sigma \Delta)$ for power electronics applications in [26], [34]. Other works extended the study of $\mathrm{H}-\Sigma \Delta$ by comparing this technique with space vector modulation (SVM) [35]. Finally, a variation of $(\mathrm{H}-\Sigma \Delta)$ known as space vector sigma-delta modulation $(\operatorname{SV} \Sigma \Delta)$ was presented recently in [36]. This last technique has been applied in three-level converters [37] and multilevel converters [38], [39]. Nevertheless, all these previous works apply $\Sigma \Delta$ and their variants using insulated-gate bipolar transistors (IGBT) at low sampling frequencies of $20 \mathrm{kHz}$, at maximum. Only in [40] the authors study the effect of another $\Sigma \Delta$ variant at high switching frequencies, the dynamic hysteresis sigma-delta modulation (DHSDM). The DHSDM is simulated in a voltage source converter (VSC) based on GaN transistors switching at $2 \mathrm{MHz}$.

Applying $\Sigma \Delta$ at such low sampling frequencies has some important drawbacks. As we mentioned before, a high oversampling ratio improves the resolution of the modulations. Thus, at low sampling frequencies, the error of synthesized voltages may be significant. Moreover, the variable switching frequency of $\Sigma \Delta$ modulations spreads the switching harmonics over a broad frequency range. A low sampling frequency generates low-order harmonics in the output voltages, but the harmonics are displaced to higher frequencies as the oversampling ratio increases [22], [23]. To filter out these loworder harmonics, power converters should have bulky output inductances, which limits the applicability of $\Sigma \Delta$ converters for energy injection into the grid.

Although $\Sigma \Delta$ modulations are usually used in audio applications, its use is scarce in power electronics. Thus, there are no complete studies about the efficiency of these techniques, their losses, nor about the produced total harmonic distortion (THD). Since the few previous studies are performed at low frequencies, the studies about the voltage frequency spectrum are also limited.

This paper studies and proposes the use of $\mathrm{H}-\Sigma \Delta$ and $\mathrm{DH}-$ $\Sigma \Delta$ with a high oversampling ratio for a VSC based on WBG semiconductors (see Fig. 1). The proposed modulations allow:

1) Working with a variable switching frequency and, consequently, reducing the switching losses.

2) Mitigating the low-order harmonics.

Moreover, we perform a theoretical study of $\mathrm{H}-\Sigma \Delta$ and $\mathrm{DH}-\Sigma \Delta$ with stability, efficiency and spectral analyses. The stability analysis studies how to tune the parameters of $\mathrm{H}$ $\Sigma \Delta$ and DH- $\Sigma \Delta$ techniques to keep the system stable and minimize the output noise. The efficiency analysis includes a study of the commutations and converter losses. The spectral analysis studies the frequency spectrum and THD. The impact of both $\Sigma \Delta$ strategies is evaluated on the basis of simulation studies using the software Matlab/Simulink and PLECS. Finally, the results are experimentally validated by implementing the proposed techniques on a VSC converter. To show the benefits of the proposed $\Sigma \Delta$ techniques over other modulations techniques, at high frequency operation, the paper compares these techniques with the conventional SVPWM and also with the VSFPWM.

The rest of this paper is organized as follows. Section II introduces $\mathrm{H}-\Sigma \Delta$ and $\mathrm{DH}-\Sigma \Delta$ modulation and analyses their basis. Section III compares the behaviour of the proposed techniques with that of SVPWM and VSFPWM. Section IV validates the above results that showed the impact of the modulation techniques on real power converters. Finally, Section V summarizes the conclusions of this paper.

\section{BASIS OF THE METHOD}

The scheme of the proposed $\Sigma \Delta$ techniques is shown in Fig. 2. $H-\Sigma \Delta$ is drawn using solid black lines, while the dashed red lines mark the extra elements present in $\mathrm{DH}-\Sigma \Delta$. Both techniques have the same structure, but DH- $\Sigma \Delta$ has an additional feedback loop and integrator.

The proposed modulation techniques work in $\alpha \beta$ coordinates; the inputs of both modulations are the reference voltages

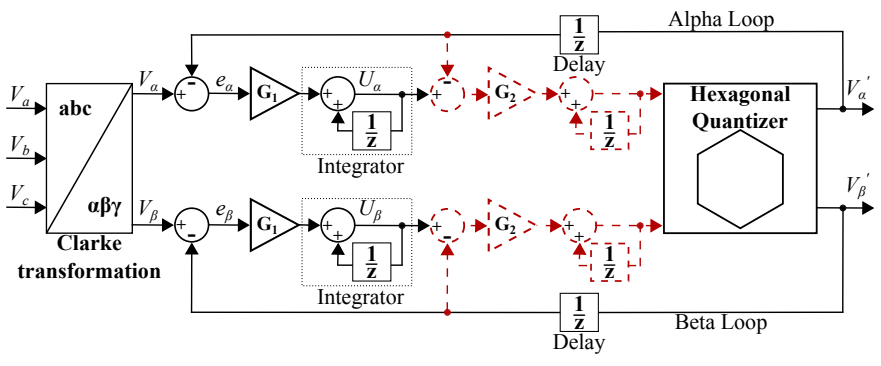

Fig. 2. Hexagonal sigma-delta modulator loop. The second integrator loop is drawn with dashed red lines. The nominal value of all gains is unity. 
in $a b c$ frame, so it is necessary to express them in $\alpha \beta$ coordinates using Clarke's transformation (1).

$$
\left[\begin{array}{l}
V_{\alpha}(t) \\
V_{\beta}(t) \\
V_{\gamma}(t)
\end{array}\right]=\frac{2}{3}\left[\begin{array}{ccc}
1 & -\frac{1}{2} & -\frac{1}{2} \\
0 & \frac{\sqrt{3}}{2} & -\frac{\sqrt{3}}{2} \\
\frac{1}{2} & \frac{1}{2} & \frac{1}{2}
\end{array}\right]\left[\begin{array}{l}
V_{a}(t) \\
V_{b}(t) \\
V_{c}(t)
\end{array}\right]
$$

These techniques compare the references $\left(V_{\alpha}, V_{\beta}\right)$ to the outputs of the quantizer $\left(V_{\alpha}^{\prime}, V_{\beta}^{\prime}\right)$ and integrate the resulting errors $\left(e_{\alpha}, e_{\beta}\right)$. There are gains before each integration, whose value may be adjusted for guaranteeing low output noise and system stability [24]. This is further studied in Section II-A. The integrated errors are the inputs of the hexagonal quantizer, whose outputs are compared to the next reference vector. The equation that describes a single-loop $\Sigma \Delta$ is:

$$
V_{x}^{\prime}(z)=V_{x}(z) z^{-1}+e_{x}(z)\left(1-z^{-1}\right),
$$

where $x=\{\alpha, \beta\}$. Notice that the quantifier type does not affect the formula.

Increasing the number of integrators is a common practice for improving $\Sigma \Delta$ modulations. DH- $\Sigma \Delta$ has two integrators, and the input of the second loop is the integrated error. Thus, a double-loop $\Sigma \Delta$ is defined using (3).

$$
V_{x}^{\prime}(z)=V_{x}(z) z^{-1}+e_{x}(z)\left(1-2 z^{-1}+z^{-2}\right)
$$

The number of integrators can be extended to any number, but in practice the modulation may become noisy when using three or more integrators [24]. For any number of integrators, (2) is rewritten as:

$$
V_{x}^{\prime}(z)=V_{x}(z) z^{-1}+e_{x}(z)\left(1-z^{-1}\right)^{N}
$$

where $N$ is the number of integrators.

The hexagonal quantizer is the core of the proposed modulation techniques. The quantizer divides the $\alpha \beta$ plane into 7 hexagonal sectors, which are the Voronoi cells of a VSC's eight switching vectors [33]. The switching states are represented by -1 and 1 , which indicate, respectively, the output voltage levels of $\frac{-V_{d c}}{2}$ and $\frac{V_{d c}}{2}$ that correspond to the midpoint of the DC bus. Fig. 3 depicts the division of the $\alpha \beta$ plane according to $\mathrm{H}-\Sigma \Delta$.

The quantizer input (i.e., the integrated error) is a random vector in $\alpha \beta$ coordinates that follows the reference vector [36].

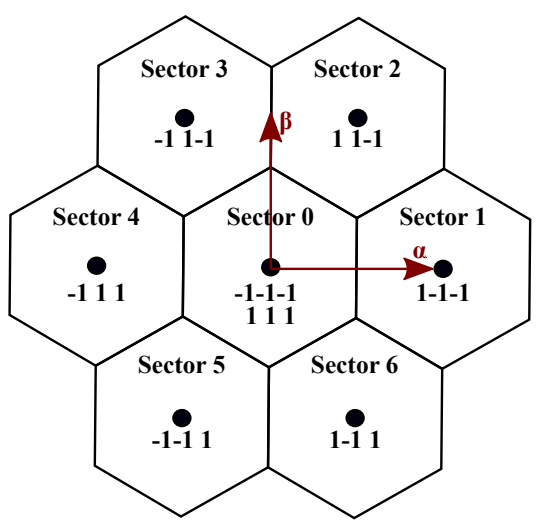

Fig. 3. Two-level vector diagram divided into sectors according to a hexagonal quantizer.
At every sampling instant, the hexagonal quantizer determines the position of the input and synthesizes it by applying the nearest switching vector. Since the $\alpha \beta$ plane is a Euclidean space, the switching vector that is closest to the input is found with (5).

$$
D_{i}^{2}=\left(V_{\alpha i}^{\prime}-U_{\alpha}\right)^{2}+\left(V_{\beta i}^{\prime}-U_{\beta}\right)^{2}
$$

where $D_{i}^{2}$ is the Euclidean distance squared from the integrated error $\left(U_{\alpha}, U_{\beta}\right)$ to the switching state $\left(V_{\alpha i}^{\prime}, V_{\beta i}^{\prime}\right)$. Calculating $D_{i}^{2}$ instead of simply $D_{i}$ allows an easier implementation of the quantizer since it avoids the complex square root operation.

The point that is closest to the reference is the switching vector with the minimum value of $D_{i}^{2}$. There are two methods for obtaining the nearest point. The first method is to calculate the distance from the reference to all switching vectors, and the nearest vector is the point with the minimum distance. The second method uses a branch and bound algorithm [41], which allows reducing the number of calculations for finding the closest point. Fig. 4 illustrates the implemented branch and bound algorithm.

Finally, the switching state of the inverter is determined from the output of the quantizer. This procedure is direct, except when the integrated error is within Sector 0. In this case, the converter has to apply one of the two zero vectors (-1-1-1 or 111). Both vectors produce the same output voltages, but the selection affects the converter losses. The proposed techniques aim to minimize losses; thus, they select the vector that reduces the number of switchings in each case. The flowchart of the proposed $\mathrm{H}-\Sigma \Delta$ and $\mathrm{DH}-\Sigma \Delta$ is depicted in Fig. 4.

\section{A. Stability analysis}

To study the system stability, this paper uses the model depicted in Fig. 5. The quantizer is represented as a source of noise. For stability purposes, it is assumed that the noise $E(z)$ is zero.

The closed-loop transfer functions are obtained from this model. The closed-loop transfer function of a $\mathrm{H}-\Sigma \Delta$ modulation is (6), while (7) is the transfer function of a DH- $\Sigma \Delta$ modulation.

$$
\begin{gathered}
G_{c l(\mathrm{H}-\Sigma \Delta)}=\frac{G_{1} z}{z-1+G_{1}} \\
G_{c l(\mathrm{DH}-\Sigma \Delta)}=\frac{G_{1} G_{2} z^{2}}{z^{2}+\left(\left(1+G_{1}\right) G_{2}-2\right) z-G_{2}+1}
\end{gathered}
$$

The system stability is determined using the previous equations. The gains $G_{1}$ and $G_{2}$ affect system stability and may increase output noise. These gains are nominally unity, but circuit imperfections can change these values. If the gains are equal to 1 , they do not generate additional noise. The noise increases as the values of gains increase or decrease [24]. Therefore, the gains must be as close to one as possible. However, if the gains are exactly 1, there are pole-zero cancellations which may cause problems. 


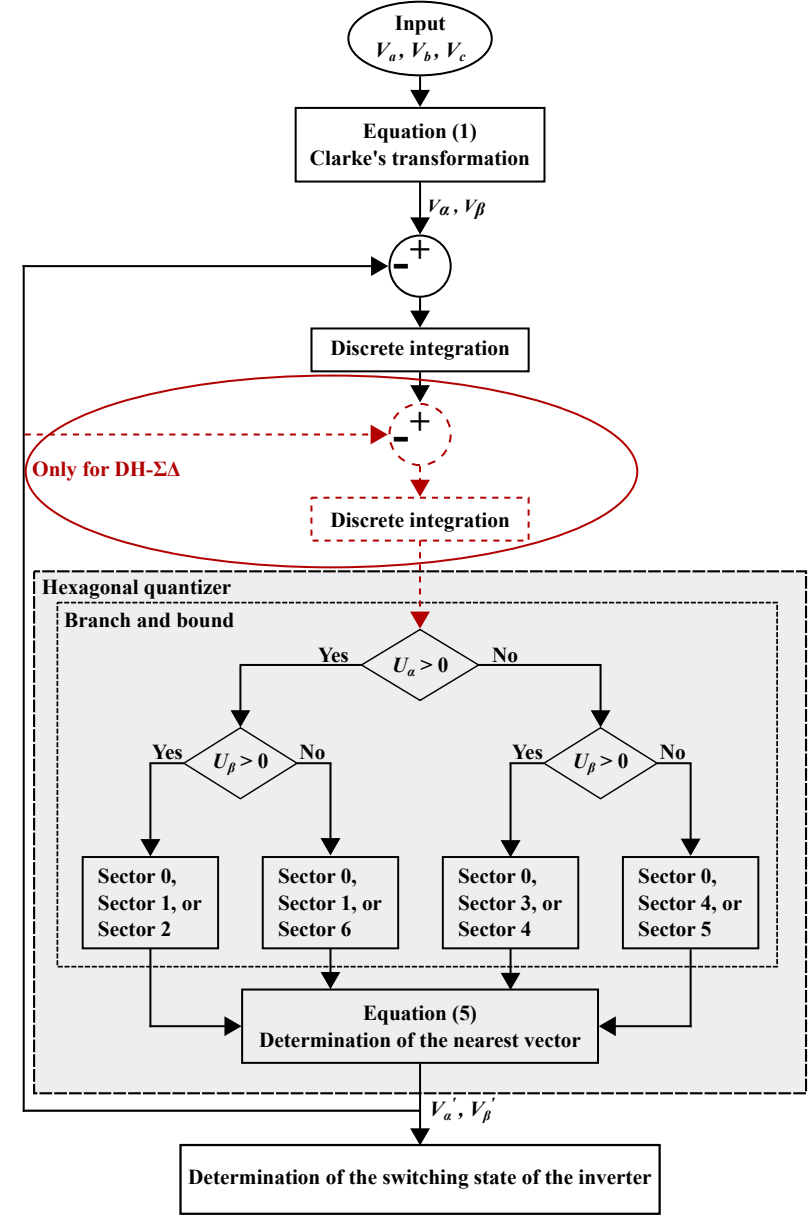

Fig. 4. Flowchart of the proposed $\Sigma \Delta$ techniques. The second integrator loop is drawn with dashed red lines.

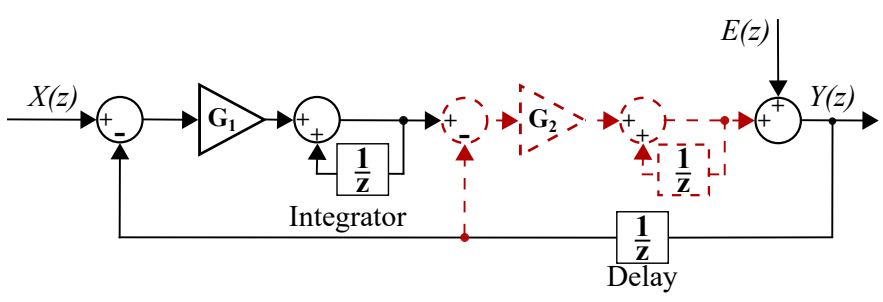

Fig. 5. Generic model of a digital $\Sigma \Delta$ modulation. The second integrator loop is drawn with dashed red lines.

Fig. 6 illustrates the z-plane of the proposed modulations using different gains. Fig. 6 (a) depicts the pole map of a H$\Sigma \Delta$. The value of $G_{1}$ affects to the poles and, thus, to the stability. The system becomes unstable at $G_{1}=2$. Fig. 6 (b) shows the poles of DH- $\Sigma \Delta$. In this map, the two gains are equal and vary from 0.9 to 1.25 . The $\mathrm{DH}-\Sigma \Delta$ always has two zeros in 0 , while the poles vary depending on $G_{1}$ and $G_{2}$. The system becomes unstable at $G_{1}=G_{2}=1.236$. DH $-\Sigma \Delta$ allows less gain variation than $\mathrm{H}-\Sigma \Delta$ does.

\section{Simulation Results}

This section evaluates the impact of the proposed $\mathrm{H}-\Sigma \Delta$ and DH- $\Sigma \Delta$ techniques on the VSC with SiC MOSFETs in Fig. 1. To assess the effects of the proposed modulations, the results

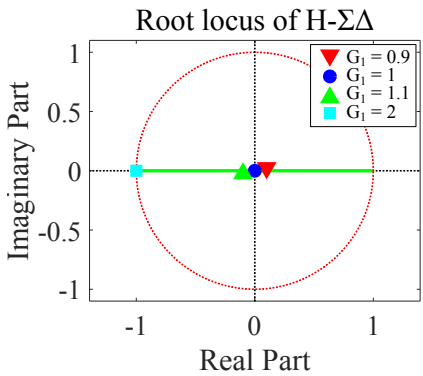

(a)

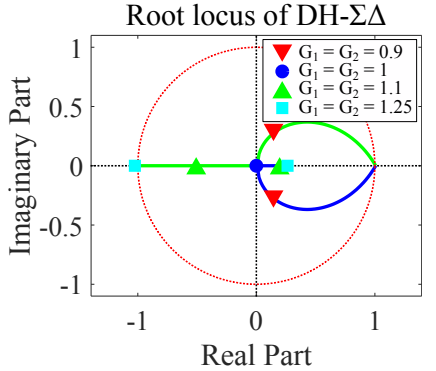

(b)
Fig. 6. Root locus analysis, using different gains, of: $\mathrm{H}-\Sigma \Delta$; and (b) $\mathrm{DH}-\Sigma \Delta$.

are compared with those of the SVPWM and the VSFPWM strategies.

An important difference between SVPWM, VSFPWM and $\Sigma \Delta$ techniques is the switching frequency. Since this parameter is variable in VSFPWM, H- $\Sigma \Delta$ and $\mathrm{DH}-\Sigma \Delta$, this work uses the maximum switching frequency as a comparison parameter. The maximum switching frequency $\left(f_{\max }\right)$ is defined as follows:

$$
f_{\text {max }}=\left\{\begin{array}{ll}
f_{s w} & \text { for SVPWM } \\
f_{s} & \text { for VSFPWM } \\
f_{s} / 2 & \text { for } \mathrm{H}-\Sigma \Delta, \text { and DH- } \Sigma \Delta
\end{array},\right.
$$

where $f_{s w}$ is the switching frequency and $f_{s}$ is the sampling frequency.

The VSFPWM requires fixing other parameters: the minimum frequency and the required current ripple. In this work, the minimum frequency is set to half the maximum. The required current ripple is fixed to be the same than those of SVPWM in the same conditions.

The studied VSC is modelled using Matlab/Simulink and PLECS Blockset. The rated power of the converter is $24.4 \mathrm{kVA}$; the DC bus voltage is $830 \mathrm{~V}$; and the $\mathrm{AC}$-side currents are constant at their rated values $(30 \mathrm{~A})$. The $\mathrm{SiC}$ MOSFET module CCS050M12CM2 is used to simulate the converter switches. This module features a maximum drainsource voltage $\left(V_{d s}\right)$ of $1.2 \mathrm{kV}$ and a continuous drain current $\left(I_{d}\right)$ of $87 \mathrm{~A}$. Each SiC MOSFET has an external gate resistance of $10 \Omega$, and their junction temperatures are $125^{\circ} \mathrm{C}$. The PLECS software calculates the losses according to the thermal datasheet and the equations provided by the manufacturer [42].

\section{A. Efficiency analysis}

This section analyses the efficiency of the proposed techniques under various operating conditions. To do this, we first analysed the commutations. In a fixed-frequency modulation technique such as SVPWM, the number of commutations per transistor $\left(N o_{s w}=2 f_{s w} / f_{o}\right)$ depends on the switching frequency and the fundamental frequency $\left(f_{o}\right)$. However, the switching frequency is variable in VSFPWM, $\mathrm{H}-\Sigma \Delta$ and DH$\Sigma \Delta$ as is the number of commutations.

Fig. 7 illustrates the number of switchings produced by the $\mathrm{H}-\Sigma \Delta$ and $\mathrm{DH}-\Sigma \Delta$ techniques. Fig. 7 (a) compares 
the number of $\mathrm{H}-\Sigma \Delta$ switchings to those of SVPWM and VSFPWM. The modulation index $(m)$ affects the number of commutations when we apply $\mathrm{H}-\Sigma \Delta$, and the maximum number of switchings is always between 0.5 and 0.6. The number of commutations is also affected by the maximum frequency; thus, these two parameters are proportional. In general, the $\mathrm{H}-\Sigma \Delta$ technique exhibits fewer commutations than SVPWM and VSFPWM. For some operating conditions at $200 \mathrm{kHz}, \mathrm{H}-\Sigma \Delta$ switches slightly more than VSFPWM does at $100 \mathrm{kHz}$, which means they produce equal losses. At $300 \mathrm{kHz}, \mathrm{H}-\Sigma \Delta$ exhibits lower commutations than VSFPWM at $200 \mathrm{kHz}$ for all operating points. Furthermore, at high modulation indexes from 0.8 onwards, this technique shows fewer switchings than the SVPWM at $100 \mathrm{kHz}$. Fig. 7 (b) compares the commutations of $\mathrm{DH}-\Sigma \Delta$ at different frequencies with SVPWM and VSFPWM at $100 \mathrm{kHz}$. In this case, the number of switchings decreases as the modulation index increases. This technique exhibits more commutations than $\mathrm{H}-\Sigma \Delta$ at low modulation indexes. However, from $m=0.4$ upward, only minor differences exist between the numbers of switchings for both $\Sigma \Delta$ techniques at all the studied frequencies.

Fig. 8 plots the ratio of the total losses of the converter, specifically by comparing the $\mathrm{H}-\Sigma \Delta$ and $\mathrm{DH}-\Sigma \Delta$ strategies to SVPWM and VSFPWM. Figs. 8 (a) and (b) illustrate the comparison with the SVPWM technique. As shown in Fig. 8 (a), the total losses of $\mathrm{H}-\Sigma \Delta$ are smaller than those produced by SVPWM under all operating conditions. Fig. 8 (b) shows equivalent results for the $\mathrm{DH}-\Sigma \Delta$ technique. In this scenario, the reduction in losses is similar to in the previous one. However, DH- $\Sigma \Delta$ causes more switchings than $\mathrm{H}-\Sigma \Delta$ at low modulation indexes. Hence, $\mathrm{H}-\Sigma \Delta$ exhibits better performance at those operating points. Figs. 8 (c) and (d) display the comparison with the VSFPWM modulation. For all operating conditions, both modulations show fewer losses than VSFPWM. Again, $\mathrm{H}-\Sigma \Delta$ exhibits better performance than DH $-\Sigma \Delta$ at low modulation indexes, since the first produces fewer commutations. However, since the VSFPWM produces fewer losses tan the SVPWM technique, these ratios are overall higher.
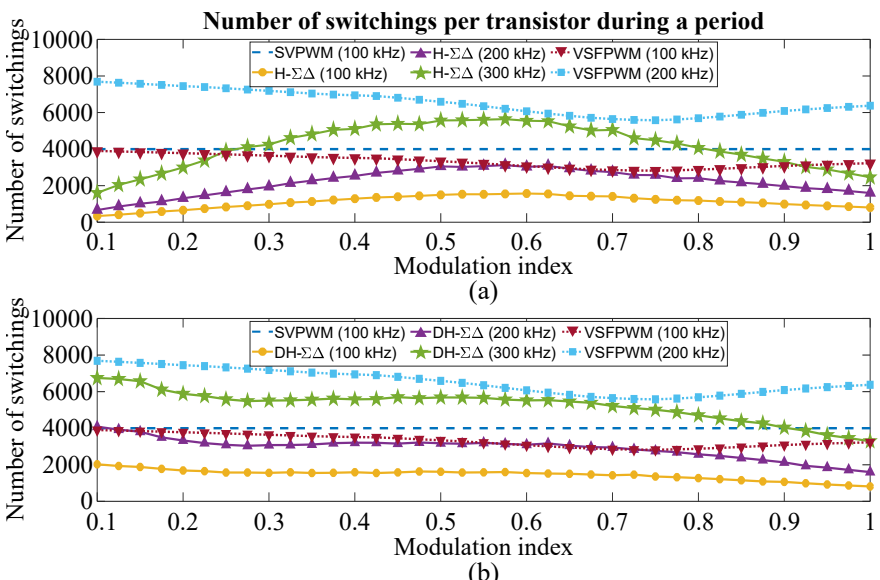

(b)

Fig. 7. Comparison of transistor switchings during a period using: (a) $\mathrm{H}-\Sigma \Delta$ and PWM techniques; (b) DH- $\Sigma \Delta$ and PWM modulations.

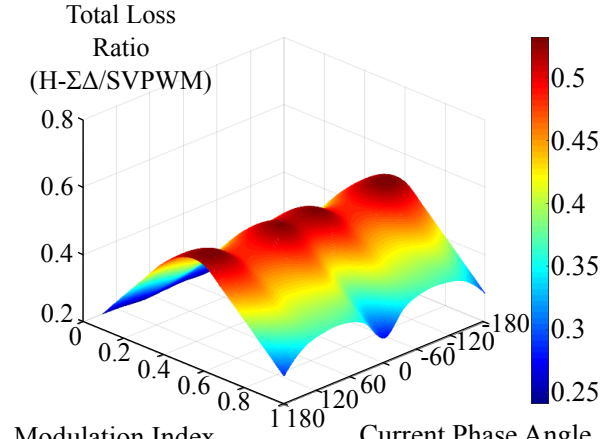

Modulation Index,

$m$

(a)

Current Phase Angle,

Total Loss Ratio

(DH- $\Delta \Delta /$ SVPWM) $\phi$ (Degrees)

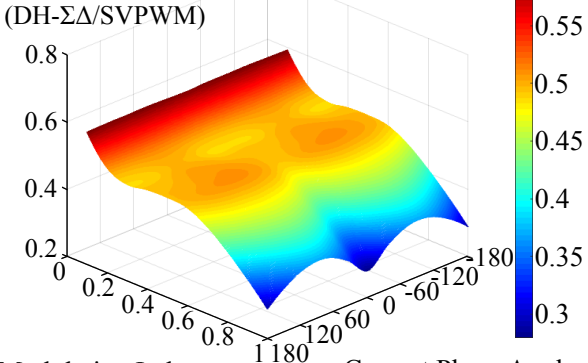

Modulation Index, $m$

(b) $\quad \phi$ (Degrees)

$$
\text { Total Loss }
$$$$
\text { Ratio }
$$

(H- $\Sigma \Delta$ /VSFPWM)

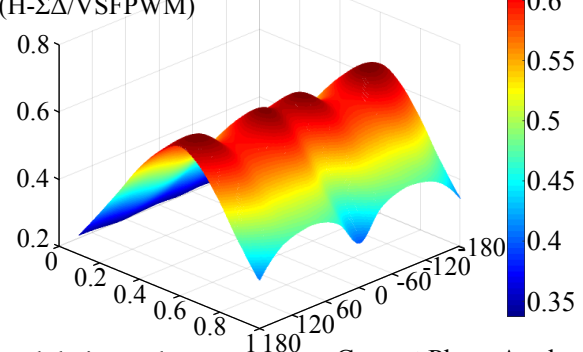

Modulation Index,

$m$

(c) $\phi$ (Degrees)

$$
\text { Total Loss }
$$$$
\text { Ratio }
$$

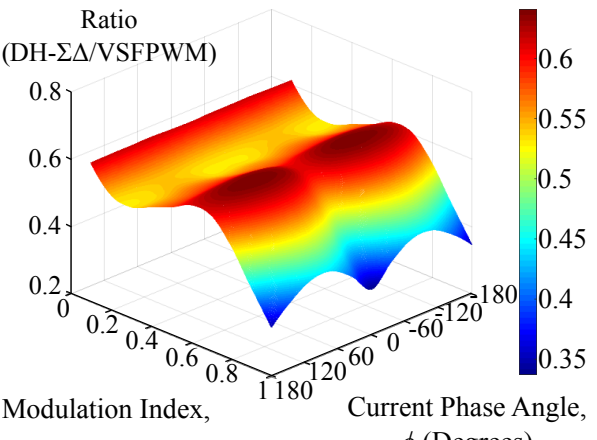

$m$

(d)

Fig. 8. Ratio of total losses at $f_{\max }=200 \mathrm{kHz}$ : (a) and (b) ratios with SVPWM; (c) and (d) ratios with VSFPWM.

\section{B. Spectral analysis}

This section studies the frequency spectrum of the proposed techniques, including the harmonic distribution and the voltage THD. The results are given in relative units of either $\mathrm{dB}$ or \%, with the values having been measured from the fundamental 
voltage.

Fig. 9 illustrates the frequency spectrum of all the studied modulations. These spectra contain three different parts. The first part covers the first 40 harmonics ranging from 0 to $2 \mathrm{kHz}$. The standard EN 50160 limits the emissions inside this range [43], which are usually harmonics. The second part ranges from 2 to $150 \mathrm{kHz}$. No standards exist for limiting the electromagnetic interferences (EMI) at these frequencies, but this paper considers an attenuation of $-40 \mathrm{~dB}$ to be acceptable. The last range begins at $150 \mathrm{kHz}$ and is covered by two international standards: IEC 61000-6-3 and IEC 61000-6-4 [44], [45]. EMIs within this range are normally conducted. Fig. 9 (a) displays the frequency spectrum produced by SVPWM. This modulation technique does not produce significant harmonics at low frequencies, but it does do so at the switching frequency and its multiples. Fig. 9 (b) depicts the frequency spectrum of VSFPWM. The first 40 harmonics are similar than those of SVPWM. From $1 \mathrm{kHz}$ to $100 \mathrm{kHz}$, this modulation produces the lowest distortion among the studied techniques. From $100 \mathrm{kHz}$ onwards, the harmonics increase since the converter switches between 100 and $200 \mathrm{kHz}$. From $150 \mathrm{kHz}$, there are significant harmonics at the multiples of the switching frequencies. Fig. 9 (c) plots the frequency spectrum of $\mathrm{H}-$ $\Sigma \Delta$. The first 40 harmonics are lower than those of SVPWM, but after $40 \mathrm{kHz}$ some harmonics are somewhat higher than $-40 \mathrm{~dB}$. At high frequencies $(>150 \mathrm{kHz})$, nearly all the harmonics are properly mitigated. This behaviour originates from the variable switching frequency that spreads the harmonics over non-critical frequencies. Hence, $\mathrm{H}-\Sigma \Delta$ is better than SVPWM for complying with the abovementioned standards. Finally, Fig. 9 (d) depicts the line voltage frequency spectrum produced by $\mathrm{DH}-\Sigma \Delta$. This spectrum is similar to that of $\mathrm{H}-$ $\Sigma \Delta$. However, this technique produces some differences in the frequency domain: at up to $2 \mathrm{kHz}$, the harmonics are the lowest among the studied techniques; at $35 \mathrm{kHz}$, harmonics greater than $-40 \mathrm{~dB}$ begin to appear; then from $150 \mathrm{kHz}$ onward, this modulation presents slightly lower harmonics than $\mathrm{H}-\Sigma \Delta$.

Fig. 10 compares the voltage THD produced by the SVPWM, VSFPWM and $\Sigma \Delta$ techniques at different frequencies. The voltage THD measurement considers only the first 40 harmonics, as detailed in the standard EN 50160 [43]. Fig. 10 (a) plots the results at $100 \mathrm{kHz}$. At $100 \mathrm{kHz}$, the SVPWM always exhibits better THD than those of $H-\Sigma \Delta$. The VSFPWM technique shows THD similar than those of SVPWM. Thus, this technique also produces less distortion than $\mathrm{H}-\Sigma \Delta$. The $\mathrm{H}-\Sigma \Delta$ modulation shows the worst THD among all the studied techniques. However, DH- $\Sigma \Delta$ shows better THD than SVPWM for all the operating points. From $m=0.9$ upward, the distortions of $\mathrm{DH}-\Sigma \Delta$ are similar to those of SVPWM. Fig. 10 (b) depicts the THD produced at $200 \mathrm{kHz}$. As the maximum frequency increases, the distortion of PWM techniques grows due to their higher carrier sideband harmonics [46], while the THD decreases using both $\Sigma \Delta$ modulations. Increasing the oversampling frequency in $\Sigma \Delta$ modulations enhances the effective number of bits; thus, the resolution grows [23], and the distortion decreases. Hence, the $\Sigma \Delta$ techniques show better THD at this frequency for all operating points. Among $\Sigma \Delta$ techniques, $\mathrm{DH}-\Sigma \Delta$ always
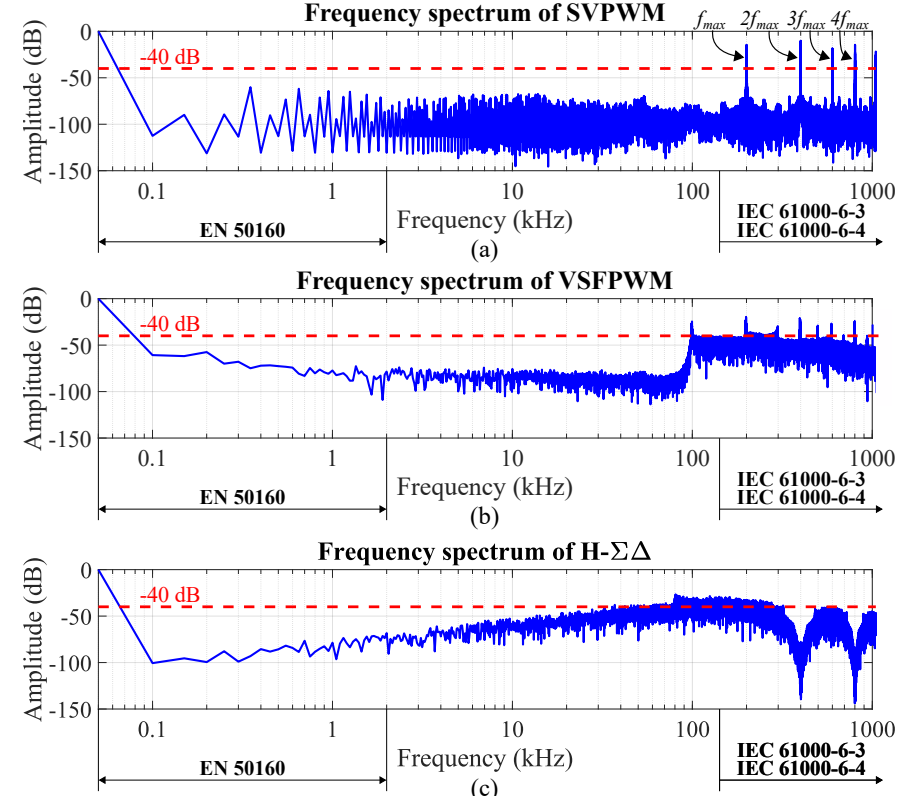

(c)

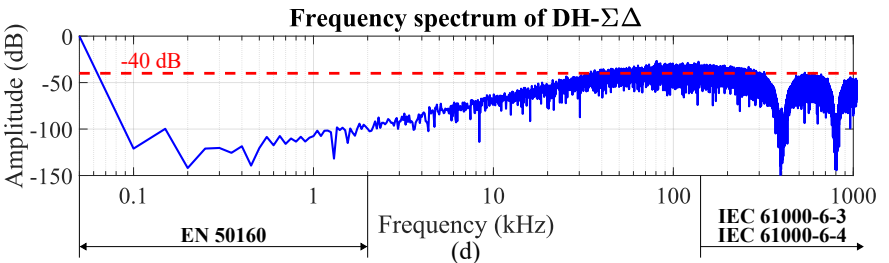

(d)

Fig. 9. Frequency spectrum of line voltage $\left(V_{a b}\right)$ using: (a) SVPWM, (b) VSFPWM, (c) $\mathrm{H}-\Sigma \Delta$, and (d) $\mathrm{DH}-\Sigma \Delta$. Modulation index: $\mathrm{m}=0.8$. Maximum frequency: $f_{\max }=200 \mathrm{kHz}$. The dashed red line marks $-40 \mathrm{~dB}$.

produces less distortion than $\mathrm{H}-\Sigma \Delta$.

\section{EXPERIMENTAL RESULTS}

To experimentally evaluate the proposed modulation techniques for the VSC converter in Fig. 1, we used a scaleddown prototype that incorporated the previously simulated SiC MOSFETs (CCS050M12CM2). On the AC side, there was a three-phase series-connected RL load with $R=68 \Omega$ and $L=1.55 \mathrm{mH}$. The DC side of the converter was supplied by a constant $300 \mathrm{~V}$ DC source. The modulation techniques were implemented on a dSPACE DS1006 platform and a DS5203 FPGA board. Voltages and currents were measured with a high-resolution oscilloscope (Agilent InfiniiVision MSO7104A: $1 \mathrm{GHz}$ bandwidth and $4 \mathrm{GS} / \mathrm{s}$ sample rate); high voltage differential probes (PMK BumbleBee: $400 \mathrm{MHz}$ bandwidth); and current probes (Keysight N2783B: $100 \mathrm{MHz}$ bandwidth). The obtained data are processed with Matlab software to calculate the THD and the voltage frequency spectrum. The converter efficiency was measured using a digital power meter (Yokogawa WT1600: $1 \mathrm{MHz}$ bandwidth). Fig. 11 shows the experimental setup.

\section{A. Experimental performance}

To evaluate the power loss reduction in $\mathrm{H}-\Sigma \Delta$ and $\mathrm{DH}-$ $\Sigma \Delta$, we measured the efficiency of the different techniques. Fig. 12 shows the converter efficiency when using the four 
Total Harmonic Distortion at $100 \mathrm{kHz}$

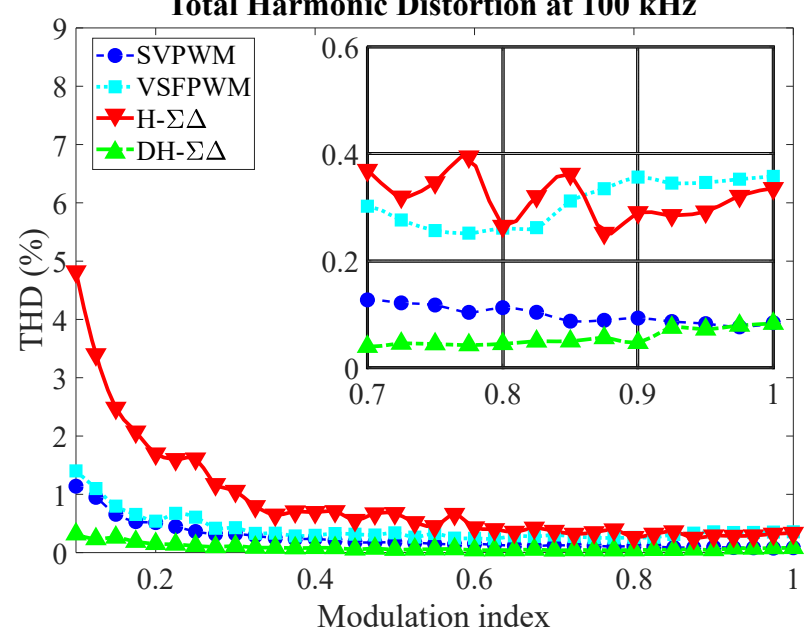

(a)

Total Harmonic Distortion at $200 \mathrm{kHz}$

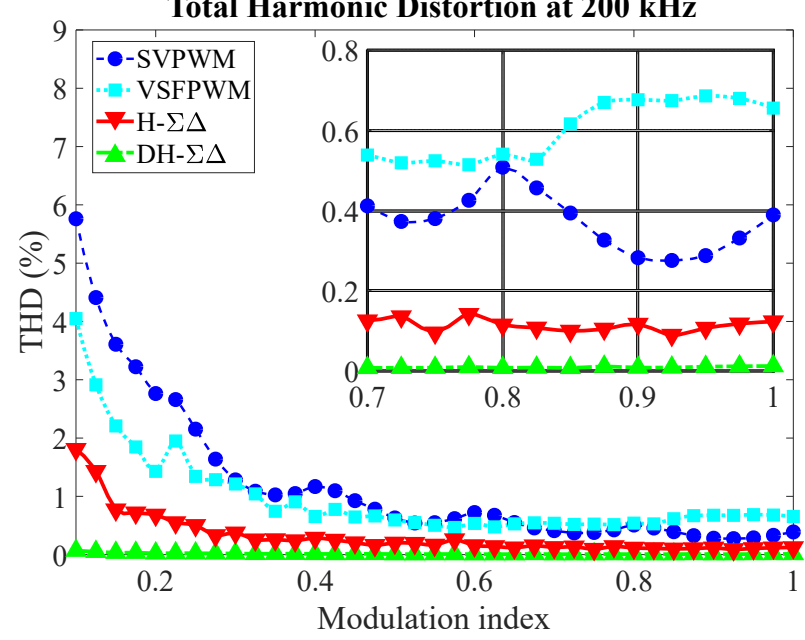

(b)

Fig. 10. Comparison of line voltage THD $\left(V_{a b}\right)$ at: (a) $f_{\max }=100 \mathrm{kHz}$; and (b) $f_{\max }=200 \mathrm{kHz}$.

techniques at 20, 100 and $200 \mathrm{kHz}$. Fig. 12 (a) illustrates the converter performance at $20 \mathrm{kHz}$. At this frequency, the performance of SVPWM and VSFPWM increases along with the modulation index, but the operating point barely affects the $\Sigma \Delta$ techniques. The efficiency of both $\Sigma \Delta$ techniques is similar and always greater than $93 \%$. Fig. 12 (b) depicts the efficiency at $100 \mathrm{kHz}$. Under this operating condition, the efficiency of both PWM techniques considerably decreases, especially at low modulation indexes. The same statement is true for $\mathrm{H}-\Sigma \Delta$ and $\mathrm{DH}-\Sigma \Delta$, but drop in efficiency is less significant. At this frequency, the performance of the four techniques increases with the modulation index. Both $\Sigma \Delta$ techniques show similar performances for modulation indexes greater than 0.4 , but $\mathrm{H}-\Sigma \Delta$ shows slightly better efficiency for all the operating points. The efficiency difference among the studied techniques reaches a minimum for high modulation indexes. At these indexes, SVPWM shows a performance of around $90 \%$ and VSFPWM exhibits an efficiency of $91 \%$. Both $\Sigma \Delta$ modulations have efficiencies greater than $95 \%$. Finally, Fig. 12 (c) plots the results at $200 \mathrm{kHz}$. At this

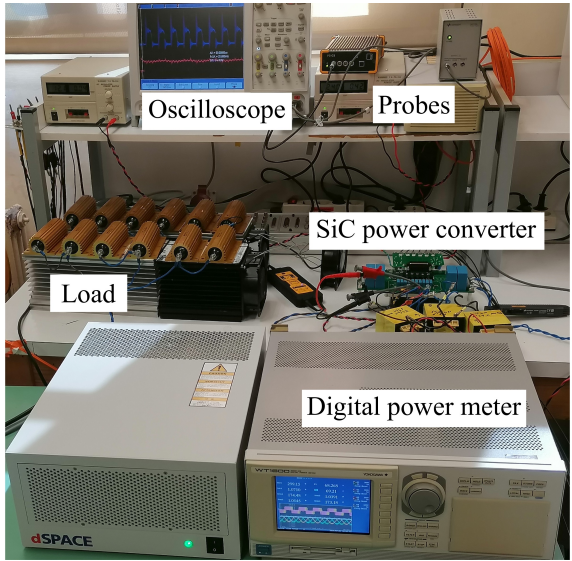

Fig. 11. View of the voltage source converter and the experimental setup.

frequency, the four techniques have the same behaviour as at $100 \mathrm{kHz}$. All the modulations are less efficient at $200 \mathrm{kHz}$ because of their higher number of switchings. However, the difference between the efficiency of the SVPWM, VSFPWM, and $\Sigma \Delta$ techniques is more significant. In this scenario, the maximum efficiency of SVPWM is around $80 \%$, while both $\Sigma \Delta$ modulations have a maximum performance somewhat higher than $91 \%$. VSFPWM always shows better efficiency than SVPWM, but its maximum efficiency is $82.2 \%$. H$\Sigma \Delta$ has higher efficiency than DH- $\Sigma \Delta$ for all the operating points. However, this efficiency difference decreases as the modulation index increases. At high modulation indexes, the difference between $\Sigma \Delta$ modulations is around $1 \%$.

\section{B. Experimental harmonic distortion}

In order to analyse the quality of $\Sigma \Delta$ modulations, we compared the line voltages and output currents produced by these two techniques with those obtained from the PWM techniques. The frequency spectrum of the line voltages $\left(V_{a b}\right)$ obtained at $f_{\max }=200 \mathrm{kHz}$ and $m=0.8$ are depicted in Fig. 13 (a). All the experimental spectra are comparable to those obtained by simulation (Fig. 9). The four techniques show low distortion, of less than $-40 \mathrm{~dB}$ at frequencies up to $2 \mathrm{kHz}$. Both $\Sigma \Delta$ techniques exhibit slightly lower distortion than PWM modulations, but $\mathrm{DH}-\Sigma \Delta$ shows the best quality at those low frequencies. Between 2 and $150 \mathrm{kHz}$, the spectra of PWM modulations have notable differences compared with those of the $\Sigma \Delta$ techniques. All the harmonics produced by PWM techniques remain below $-40 \mathrm{~dB}$, but the distortion of both $\Sigma \Delta$ techniques begin to grow and reach their maximum. The $\mathrm{H}-\Sigma \Delta$ spectrum shows that the distortion rises after $4 \mathrm{kHz}$, while the increase in the DH- $\Sigma \Delta$ spectrum begins at $10 \mathrm{kHz}$. The maximum harmonics of both $\Sigma \Delta$ techniques have comparable values and are somewhat higher than $-40 \mathrm{~dB}$. From the maximum switching frequency of $200 \mathrm{kHz}$ onwards, SVPWM exhibits significant harmonics at the switching frequency and its multiples, while the $\Sigma \Delta$ techniques show much lower harmonics. Since the implemented VSFPWM technique switches from 100 to $200 \mathrm{kHz}$, it produces more distortion from $100 \mathrm{kHz}$ onwards. However, this technique 


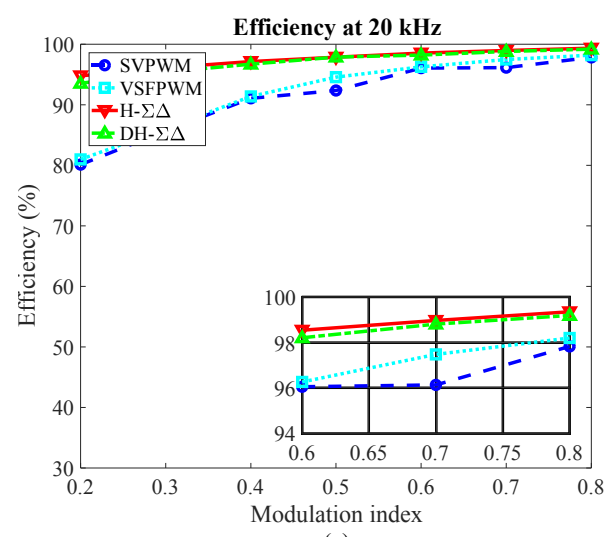

(a)

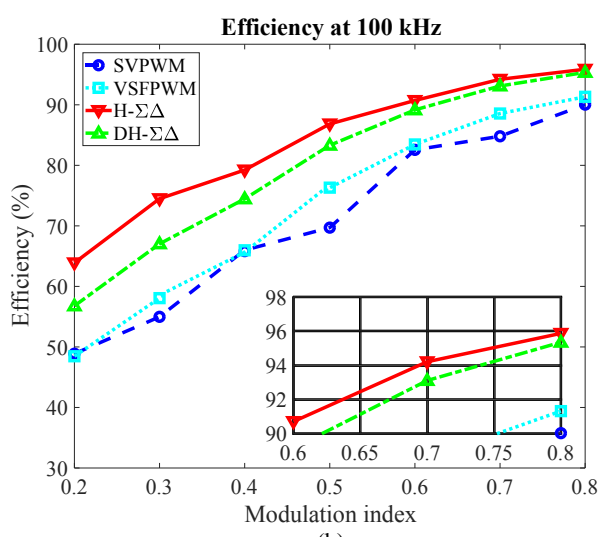

(b)

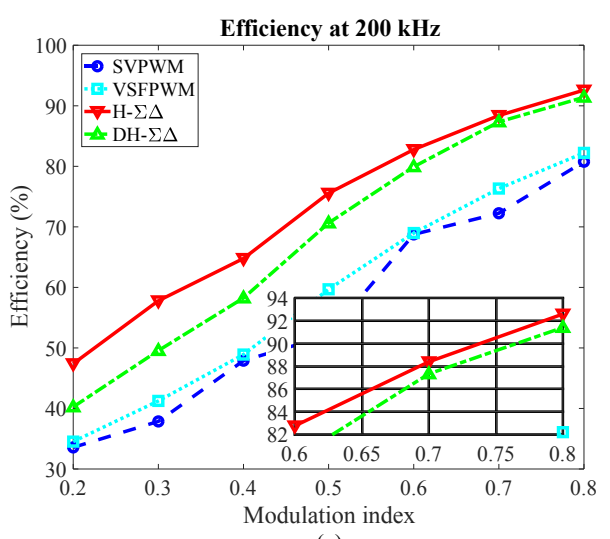

(c)

Fig. 12. Converter efficiency curves at: (a) $f_{\max }=20 \mathrm{kHz}$; (b) $f_{\max }=100 \mathrm{kHz}$; and (c) $f_{\max }=200 \mathrm{kHz}$.

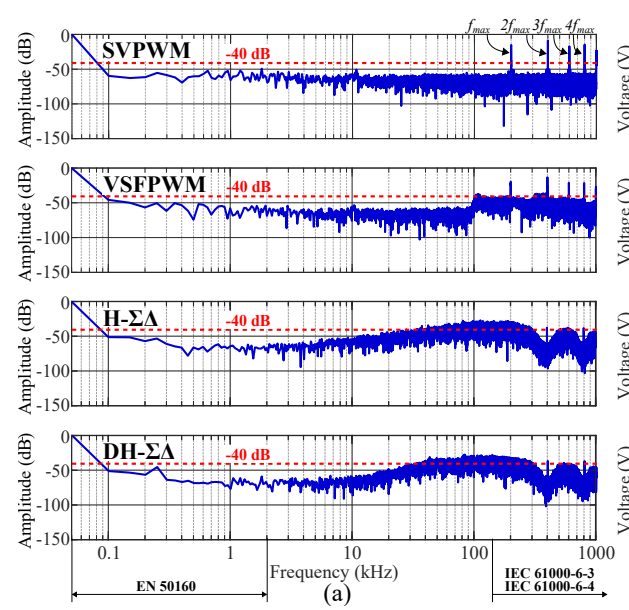

(a)

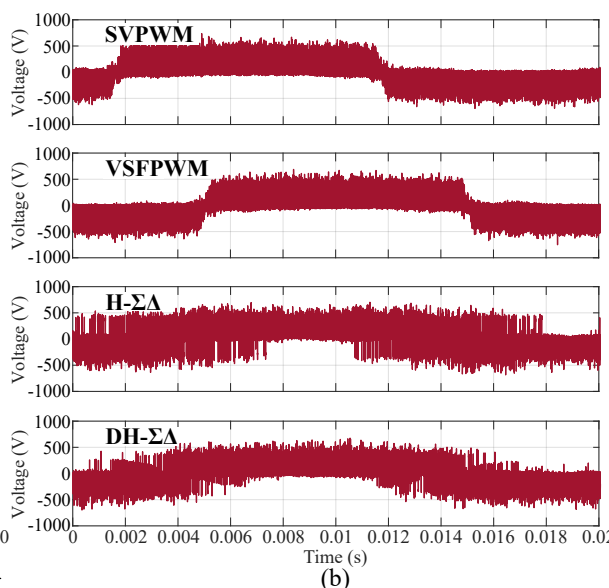

(b)

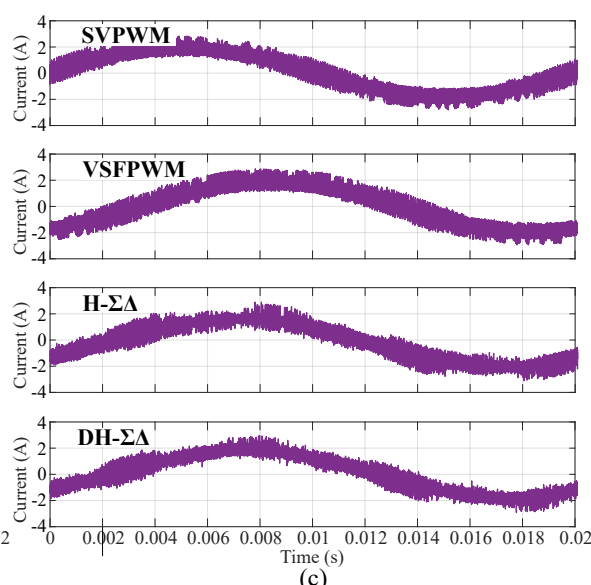

(c)

Fig. 13. Experimental results obtained at high frequency $(200 \mathrm{kHz})$ and $m=0.8$ : (a) frequency spectrum of line voltage $\left(V_{a b}\right)$; (b) line voltage $\left(V_{a b}\right)$; and (c) converter output current $\left(I_{a}\right)$.

generates smaller harmonics than the SVPWM at the maximum switching frequency and its multiples. There are no notable differences between $\mathrm{H}-\Sigma \Delta$ and $\mathrm{DH}-\Sigma \Delta$ within this frequency range.

Fig. 13 (b) depicts the line voltages $\left(V_{a b}\right)$ produced by the four studied techniques. PWM voltages have a cleaner waveform than the others. Some distortion appears in all of them, but it is more notable for the $\mathrm{H}-\Sigma \Delta$ and $\mathrm{DH}-\Sigma \Delta$ techniques, both of which spread the harmonics over a wide frequency range. Moreover, $\Sigma \Delta$ modulations may switch two phases at once and, thus, produce some voltage spikes.

Fig. 13 (c) illustrates the converter output current. All the techniques produce a sinusoidal current and, hence, all of them work correctly. The distortion is also similar for all the currents, so there are no notable differences between them.

In order to confirm the better harmonic distortion of $\Sigma \Delta$ modulations at low frequencies, the THD of the different techniques has been calculated from the obtained measurements. Fig. 14 illustrates the line voltage THD when using the studied techniques for different maximum frequencies. As described by the standard EN 50160, all the harmonics of up to $2 \mathrm{kHz}$ have been computed [43]. At $20 \mathrm{kHz}$, the THD of SVPWM is below $1 \%$ for all the operating points, while the THD of both $\Sigma \Delta$ techniques is extremely high. The severe distortion of $\Sigma \Delta$ techniques has limited their applicability in power converters until the present, now that WBG devices allow switching at higher frequencies. However, the distortion of DH- $\Sigma \Delta$ considerably decreases with the modulation index. At high indexes, its THDs are similar to those of VSFPWM. At $100 \mathrm{kHz}$, the THD of PWM modulations are slightly higher, but they decrease as the modulation index increases. Moreover, the THD of both $\Sigma \Delta$ techniques is much better than at $20 \mathrm{kHz}$. $\mathrm{H}-\Sigma \Delta$ exhibits similar distorion than VSFPWM for all the operating points, but DH- $\Sigma \Delta$ shows THDs that are comparable to those of SVPWM. Nonetheless, SVPWM continues to generate the lowest harmonic distortion. At $200 \mathrm{kHz}$, the THD of both PWM techniques is somewhat higher than at $100 \mathrm{kHz}$ for all the operating points. $\mathrm{H}-\Sigma \Delta$ has lower THDs than at $100 \mathrm{kHz}$ for all the studied modulation indexes, and DH- $\Sigma \Delta$ presents about the same distortion levels. At this frequency, DH- $\Sigma \Delta$ is the best option in terms of distortion, closely followed by $\mathrm{H}-\Sigma \Delta$. Both $\Sigma \Delta$ techniques produce less THD than SVPWM and VSFPWM do. Thus, at $200 \mathrm{kHz}$, the situation is the opposite of what occurs at $20 \mathrm{kHz}$.

Table I presents in detail the experimental results shown by Figs. 12 and 14. 
TABLE I

DETAIL OF THE EXPERIMENTAL RESULTS

\begin{tabular}{|c|c|c|c|c|c|c|c|c|c|c|c|c|}
\hline \multirow{3}{*}{$\begin{array}{l}\text { Maximum } \\
\text { frequency } \\
\left(f_{\max }\right)\end{array}$} & \multirow{3}{*}{$\begin{array}{l}\text { Modulation } \\
\text { technique }\end{array}$} & \multicolumn{7}{|c|}{ Efficiency (\%) } & \multicolumn{4}{|c|}{ THD (\%) } \\
\hline & & \multicolumn{7}{|c|}{ Modulation index } & \multicolumn{4}{|c|}{ Modulation index } \\
\hline & & 0.2 & 0.3 & 0.4 & 0.5 & 0.6 & 0.7 & 0.8 & 0.2 & 0.4 & 0.6 & 0.8 \\
\hline \multirow[t]{4}{*}{$20 \mathrm{kHz}$} & SVPWM & 80.12 & 85.70 & 91.07 & 92.36 & 96.06 & 96.14 & 97.83 & 0.26 & 0.14 & 0.21 & 0.11 \\
\hline & VSFPWM & 80.98 & 86.06 & 91.38 & 94.57 & 96.27 & 97.48 & 98.20 & 0.70 & 0.58 & 1.86 & 2.41 \\
\hline & $\mathrm{H}-\Sigma \Delta$ & 94.78 & 96.12 & 97.14 & 97.86 & 98.54 & 98.97 & 99.35 & 10.14 & 4.60 & 4.44 & 3.44 \\
\hline & DH- $\Sigma \Delta$ & 93.55 & 95.40 & 96.71 & 97.88 & 98.21 & 98.81 & 99.19 & 5.33 & 2.52 & 1.97 & 1.43 \\
\hline \multirow[t]{4}{*}{$100 \mathrm{kHz}$} & SVPWM & 48.88 & 54.65 & 65.99 & 69.71 & 82.56 & 84.80 & 90.03 & 0.99 & 0.42 & 0.33 & 0.28 \\
\hline & VSFPWM & 48.46 & 58.09 & 65.16 & 76.31 & 83.45 & 88.56 & 91.32 & 2.07 & 0.94 & 0.85 & 0.84 \\
\hline & $\mathrm{H}-\Sigma \Delta$ & 63.89 & 74.49 & 79.23 & 86.84 & 90.71 & 94.21 & 95.87 & 2.01 & 0.94 & 0.72 & 0.49 \\
\hline & DH- $\Sigma \Delta$ & 56.78 & 67.03 & 74.46 & 83.31 & 89.16 & 91.11 & 95.35 & 1.08 & 0.33 & 0.33 & 0.28 \\
\hline \multirow[t]{4}{*}{$200 \mathrm{kHz}$} & SVPWM & 33.57 & 37.87 & 47.90 & 52.09 & 68.76 & 72.25 & 80.77 & 3.63 & 1.90 & 1.14 & 0.82 \\
\hline & VSFPWM & 34.53 & 41.25 & 48.91 & 56.69 & 68.98 & 76.33 & 82.22 & 3.67 & 1.55 & 1.09 & 1.31 \\
\hline & $\mathrm{H}-\Sigma \Delta$ & 47.40 & 57.79 & 64.78 & 75.56 & 82.77 & 88.40 & 92.59 & 1.86 & 0.79 & 0.66 & 0.41 \\
\hline & DH- $\Sigma \Delta$ & 40.26 & 49.57 & 58.25 & 70.64 & 79.93 & 87.34 & 91.41 & 0.98 & 0.23 & 0.23 & 0.18 \\
\hline
\end{tabular}

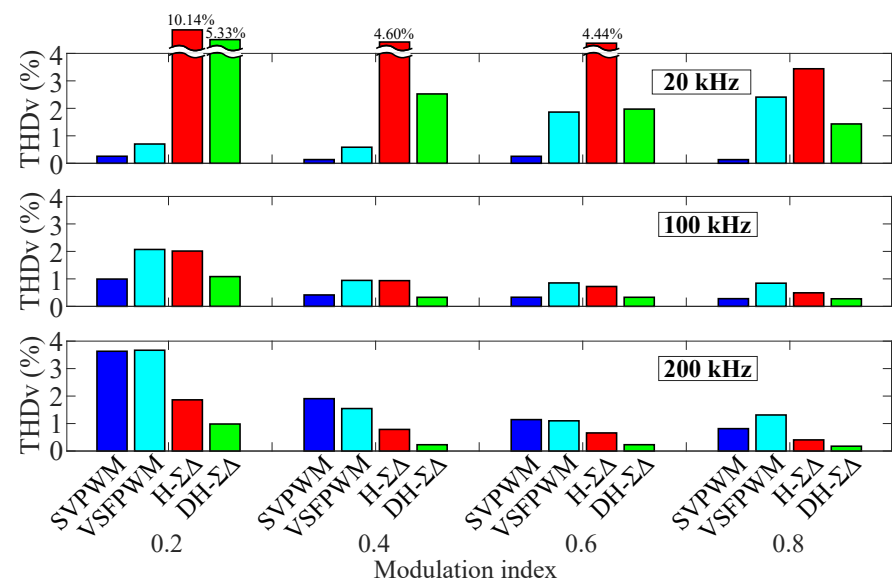

Fig. 14. THD of line voltage $\left(V_{a b}\right)$ at 20,100 and $200 \mathrm{kHz}$.

\section{CONCLUSION}

This paper proposes using $\mathrm{H}-\Sigma \Delta$ and $\mathrm{DH}-\Sigma \Delta$ for voltage source converters that use wide-bandgap power devices. The proposed $\Sigma \Delta$ modulations are an alternative to SVPWM, and other variable switching frequency techniques, for highfrequency operations. The effectiveness of the proposed techniques is demonstrated by the experimental results. Both $\Sigma \Delta$ modulations are compared to the conventional SVPWM technique and a variable switching frequency SVPWM at different frequencies. The results show that $\Sigma \Delta$ techniques do not have significant advantages for low-frequency operations, such as those of IGBTs. Nevertheless, $\mathrm{H}-\Sigma \Delta$ and DH- $\Sigma \Delta$ exhibit salient features for high-frequency operations when compared with the PWM techniques. The experiments demonstrate that both $\Sigma \Delta$ modulations decrease power losses and, thus, improve converter efficiency. Moreover, the proposed techniques reduce the low-order harmonics, such that the THDs of these techniques are lower than those produced by SVPWM. $\Sigma \Delta$ modulations also generate smaller high-order harmonics than PWM techniques. Finally, this paper concludes that the effectiveness and the benefits of $\mathrm{H}-\Sigma \Delta$ and $\mathrm{DH}-\Sigma \Delta$ increase in parallel with the operating frequency.

\section{ACKNOWLEDGMENT}

This work was supported by the Industrial Doctorates Plan of the Secretaria d'Universitats i Recerca del Departament d'Empresa i Coneixement de la Generalitat de Catalunya, and the Ministerio de Ciencia, Innovación y Universidades of Spain within the project PID2019-111420RB-I00.

\section{REFERENCES}

[1] J. Millan, P. Godignon, X. Perpina, A. Perez-Tomas, and J. Rebollo, "A survey of wide bandgap power semiconductor devices," IEEE Transactions on Power Electronics, vol. 29, no. 5, pp. 2155-2163, May 2014.

[2] K. Shenai, "High-Density Power Conversion and Wide- Bandgap Semiconductor Power Electronics Switching Devices," Proceedings of the IEEE, vol. 107, no. 12, pp. 1-19, Nov. 2019.

[3] H. Dong, H. Xue, Q. He, Y. Qin, G. Jian, S. Long, and M. Liu, "Progress of power field effect transistor based on ultra-wide bandgap Ga2O3 semiconductor material," IEEE Transactions on Power Electronics, vol. 35, no. 5, pp. 5157-5179, May 2020.

[4] I. López, E. Ibarra, A. Matallana, J. Andreu, and I. Kortabarria, "Next generation electric drives for HEV/EV propulsion systems: Technology, trends and challenges," Renewable and Sustainable Energy Reviews, vol. 114, p. 109336, 2019.

[5] K. Dang, J. Zhang, H. Zhou, S. Huang, T. Zhang, Z. Bian, Y. Zhang, X. Wang, S. Zhao, K. Wei, and Y. Hao, "A $5.8 \mathrm{GHz}$ High-power and High-efficiency Rectifier Circuit with Lateral GaN Schottky Diode for Wireless Power Transfer," IEEE Transactions on Power Electronics, vol. 35, no. 3, pp. 1-1, Mar. 2019.

[6] T. Mishima and E. Morita, "High-Frequency Bridgeless Rectifier Based ZVS Multiresonant Converter for Inductive Power Transfer Featuring High-Voltage GaN-HFET," IEEE Transactions on Industrial Electronics, vol. 64, no. 11, pp. 9155-9164, Nov. 2017.

[7] B. Li, Q. Li, F. C. Lee, Z. Liu, and Y. Yang, "A High-Efficiency HighDensity Wide-Bandgap Device-Based Bidirectional On-Board Charger," IEEE Journal of Emerging and Selected Topics in Power Electronics, vol. 6, no. 3, pp. 1627-1636, Sep. 2018.

[8] H. Li, S. Member, Z. Zhang, S. Member, S. Wang, J. Tang, X. Ren, and Q. Chen, "A 30-kHz 6.6-kW SiC Bidirectional LLC Onboard Charger," IEEE Transactions on Industrial Electronics, vol. 67, no. 2, pp. 14351445, Feb. 2020.

[9] F. Xue, R. Yu, and A. Q. Huang, "A 98.3\% Efficient GaN Isolated Bidirectional Storage System Applications," IEEE Transactions on Industrial Electronics on Industrial Electronics, vol. 64, no. 11, pp. 9094-9103, Nov. 2017.

[10] A. N. Lemmon, R. Cuzner, J. Gafford, R. Hosseini, A. D. Brovont, and M. S. Mazzola, "Methodology for characterization of commonmode conducted electromagnetic emissions in wide-bandgap converters for ungrounded shipboard applications," IEEE Journal of Emerging and Selected Topics in Power Electronics, vol. 6, no. 1, pp. 300-314, Mar. 2018. 
[11] A. K. Morya, M. C. Gardner, B. Anvari, L. Liu, A. G. Yepes, J. DovalGandoy, and H. A. Toliyat, "Wide bandgap devices in AC electric drives: Opportunities and challenges," IEEE Transactions on Transportation Electrification, vol. 5, no. 1, pp. 3-20, Mar. 2019.

[12] A. Matallana, E. Ibarra, I. López, J. Andreu, J. I. Garate, X. Jordà, and J. Rebollo, "Power module electronics in HEV/EV applications: New trends in wide-bandgap semiconductor technologies and design aspects," Renewable and Sustainable Energy Reviews, vol. 113, p. 109264, Oct. 2019.

[13] S. Ohn, J. Yu, P. Rankin, B. Sun, R. Burgos, D. Boroyevich, H. Suryanarayana, and C. Belcastro, "Three-terminal common-mode EMI model for EMI generation, propagation, and mitigation in a full-sic three-phase ups module," IEEE Transactions on Power Electronics, vol. 34, no. 9, pp. 8599-8612, Sep. 2019.

[14] S. Yin, K. J. Tseng, R. Simanjorang, Y. Liu, and J. Pou, "A 50-kW High-Frequency and High-Efficiency SiC Voltage Source Inverter for More Electric Aircraft," IEEE Transactions on Industrial Electronics, vol. 64, no. 11, pp. 9124-9134, Nov. 2017.

[15] R. Gamoudi, D. E. Chariag, and L. Sbita, "A Review of SpreadSpectrum-Based PWM Techniques - A Novel Fast Digital Implementation," IEEE Transactions on Power Electronics, vol. 33, no. 12, pp. 10 292-10 307, Dec. 2018.

[16] D. Jiang and F. F. Wang, "Variable switching frequency PWM for threephase converters based on current ripple prediction," IEEE Transactions on Power Electronics, vol. 28, no. 11, pp. 4951-4961, Nov. 2013.

[17] J. Chen, D. Jiang, W. Sun, Z. Shen, and Y. Zhang, "An improved variable switching frequency modulation strategy for three-level converters with reduced conducted EMI," in 2019 IEEE Energy Conversion Congress and Exposition, ECCE 2019. Baltimore, MD, USA: IEEE, 2019, pp. 6937-6942.

[18] L. Wei and R. A. Lukaszewski, "Pulse width modulation (PWM) rectifier with variable switching frequency," Patent US 7,190,143 B2, Mar.13, 2007.

[19] F. Yang, A. R. Taylor, H. Bai, B. Cheng, and A. A. Khan, "Using d-q transformation to vary the switching frequency for interior permanent magnet synchronous motor drive systems," IEEE Transactions on Transportation Electrification, vol. 1, no. 3, pp. 277-286, Oct. 2015.

[20] X. Zhao, X. Wang, S. Liu, C. Gu, S. Zhao, and Z. Deng, "Switching frequency variation based on current ripple analysis of a 3-1 pmsm drive system considering neutral point balance," IET Power Electronics, vol. 13, no. 4, pp. 776-787, Mar. 2020.

[21] S. Pavan, R. Schreier, and G. C. Temes, Understanding Delta-Sigma Data Converters, 2nd ed. Wiley-IEEE Press, 2017.

[22] E. Janssen and A. van Roermund, Look-Ahead Based Sigma-Delta Modulation, 1st ed. Springer Netherlands, 2011.

[23] J. Reiss, "Understanding Sigma-Delta Modulation: The Solved and Unsolved Issues," AES: Journal of the Audio Engineering Society, vol. 56, no. 1/2, pp. 49-64, Jan. 2008.

[24] J. C. Candy, "A Use of Double Integration in Sigma Delta Modulation," IEEE Transactions on Communications, vol. 33, no. 3, pp. 249-258, Mar. 1985.

[25] M. Yavari and O. Shoaei, "Low-voltage sigma-delta modulator topologies for broadband applications," in 2004 IEEE International Symposium on Circuits and Systems (ISCAS), Vancouver, BC, Canada, 2004, pp. 964-975.

[26] G. Luckjiff, I. Dobson, and D. Divan, "Interpolative Sigma Delta Modulators for High Frequency Power Electronic Applications," in Proceedings of PESC '95 - Power Electronics Specialist Conference, Atlanta, GA, USA, 1995, pp. 444-449.

[27] I. H. Kheraluwala and D. M. Divan, "Delta Modulation Strategies for Resonant Link Inverters," IEEE Transactions on Power Electronics, vol. 5, no. 2, pp. 220-228, Apr. 1990.

[28] A. Mertens, "Performance Analysis of Three-phase Delta-Modulation Systems," IEEE Transactions on Industry Applications, vol. 30, no. 4, pp. 1016-1027, Aug. 1994.

[29] A. Hirota, S. Nagai, and M. Nakaoka, "A novel delta-sigma modulated space vector modulation scheme using scalar delta-sigma modulators," in IEEE 34th Annual Conference on Power Electronics Specialist, 2003. PESC '03., Acapulco, Mexico, 2003, pp. 485-489.

[30] A. Hirota, B. Saha, S. P. Mun, and M. Nakaoka, "An advanced simple configuration delta-sigma modulation three-phase inverter implementing space voltage vector approach," in 2007 IEEE Power Electronics Specialists Conference, Orlando, FL, USA, 2007, pp. 453-457.

[31] Deepakraj M. Divan; Ian Dobson; Glen A. Luckiff, "Modulator for resonant link converters," Patent 5,619,406, Apr. 8, 1997.

[32] G. Luckjiff and I. Dobson, "Power Spectrum of a Sigma-Delta Modulator with Hexagonal Vector Quantization and Constant Input," in
1999 IEEE International Symposium on Circuits and Systems (ISCAS), Orlando, FL, USA, 1999, pp. 270-273.

[33] G. Luckjiff and I. Dobson, "Hexagonal Sigma - Delta Modulation," IEEE Transactions on Circtuits and Systems, vol. 50, no. 8, pp. 9911005, Aug. 2003

[34] G. Luckjiff and I. Dobson, "Hexagonal $\Lambda \Delta$ modulators in power electronics," IEEE Transactions on Power Electronics, vol. 20, no. 5, pp. 1075-1083, Sep. 2005.

[35] J. Nieznanski, A. Wojewodka, and P. J. Chrzan, "Comparison of vector sigma-delta modulation and space-vector PWM," in 2000 26th Annual Conference of the IEEE Industrial Electronics Society. IECON 2000, Nagoya, Japan, 2000, pp. 1322-1327.

[36] B. Jacob and M. R. Baiju, "Spread spectrum scheme for two-level inverters using space vector Sigma-Delta Modulation," in 5th IET International Conference on Power Electronics, Machines and Drives (PEMD 2010), Brighton, UK, 2010, pp. 1-6.

[37] B. Jacob and M. R. Baiju, "Spread spectrum scheme for three-level inverters based on space vector Sigma Delta Modulator," in IEEE International Symposium on Industrial Electronics, 2010, pp. 14911496.

[38] B. Jacob and M. R. Baiju, "Vector-quantized space-vector-based spread spectrum modulation scheme for multilevel inverters using the principle of oversampling ADC," IEEE Transactions on Industrial Electronics, vol. 60, no. 8, pp. 2969-2977, Aug. 2013.

[39] B. Jacob and M. R. Baiju, "A new space vector modulation scheme for multilevel inverters which directly vector quantize the reference space vector," IEEE Transactions on Industrial Electronics, vol. 62, no. 1, pp. 88-95, Jan. 2015.

[40] J. Kabziński, Advanced Control of Electrical Drives and Power Electronics. Cham, Switzerland: Springer, 2017, vol. 75.

[41] A. Land and A. Doig, "An Automatic Method of Solving Discrete Programming Problems," Econometrica, vol. 28, no. 3, pp. 497-520, Jun. 1960.

[42] PLECS User Manual, 4th ed., Plexim GmbH, Zurich, Switzerland, 2019.

[43] Voltage characteristics of electricity supplied by public electricity networks. EN 50160:2010, CENELEC, 2010.

[44] Electromagnetic compatibility (EMC). Part 6-3: Generic standards. Emission standard for residential, commercial and light-industrial environments. (IEC 61000-6-3:2006). EN 61000-6-3:2007, CENELEC, 2007.

[45] Electromagnetic compatibility (EMC). Part 6-4: Generic standards. Emission standard for industrial environments. (IEC 61000-6-4:2006). EN 61000-6-4:2007, CENELEC, 2007.

[46] D. G. Holmes, "General analytical method for determining the theoretical harmonic components of carrier based PWM strategies," in Conference Record - IAS Annual Meeting (IEEE Industry Applications Society), vol. 2, no. 2, St. Louis, MO, USA, 1998, pp. 1207-1214.

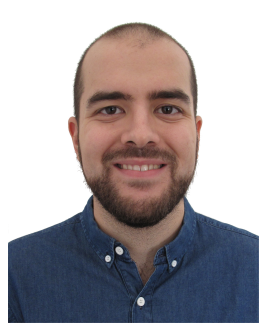

David Lumbreras (S'19) received the B.S. degree in industrial technology engineering and the M.S. degree in automatic systems and industrial electronics engineering from the Technical University of Catalonia (UPC), Barcelona, Spain, in 2017 and 2018 respectively. He is currently working toward the Ph.D. degree in the Terrassa Industrial Electronics Group (TIEG), Department of Electronic Engineering, UPC, Terrassa, Spain.

From July 2016 to January 2019, he was a CE Marking Engineer with the Certification Unit of Applus+ Laboratories, Bellaterra, Spain. Since 2019, he is a Researcher with the R\&D Power Electronics of Circutor, Viladecavalls, Spain. His research interests include modelling and control of power converters, multilevel converters, power quality, renewable energy, active power filters, electromagnetic compatibility, and modulation techniques. 


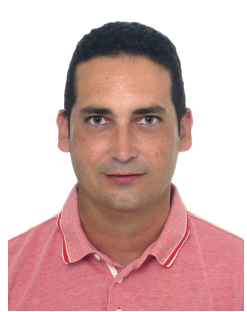

Jordi Zaragoza (S'08-M'12) received the B.S. degree in electronic engineering, the M.S. degree in automatic and electronic industrial engineering and Ph.D. degree from the Technical University of Catalonia (UPC), Catalonia, Spain, in 2001, 2004, and 2011 respectively.

In 2003, he joined the faculty of UPC as an Assistant Professor, where he became an Associate Professor in 2012. From September 2006 to September 2007 he was a researcher at the Energy Unit of ROBOTIKER-TECNALIA Technologic Corporation, Basque Country, Spain. Since 2017 he is director of the Terrassa Industrial Electronics Group (TIEG) at UPC. He is the author of more than 70 published technical papers and he has been involved in several projects in the fields of power electronics and systems. His research interests include modeling and control of power converters, multilevel converters, wind energy, power quality and HVDC transmission systems.

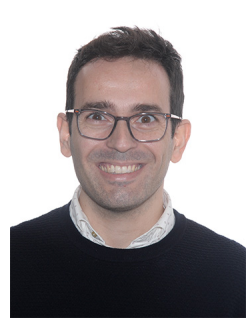

Néstor Berbel received the B.S. degree in electronics engineering, the M.S. degree in electronics engineering, and the Ph.D. degree from the Technical University of Catalonia (UPC), Barcelona, Spain, in 2002, 2004, and 2015 respectively.

In 2003, he joined the faculty of UPC as an Assistant Professor and became an Associate Professor in 2012. His scientific research has been developed at the Terrassa Industrial Electronics Group (TIEG), Department of Electronic Engineering, UPC, Terrassa, Spain. His research interests include microelectronic reliability, power converters, efficiency on power converters, modulations and control loops applied on power converters.

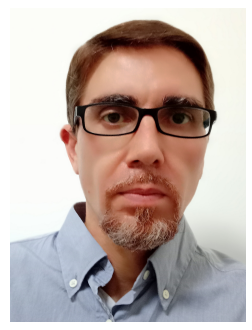

Juan Mon was born in Galicia, Spain, in 1977. He received the M.S., and Ph.D. degrees in electronics engineering from the Technical University of Catalonia (UPC), Barcelona, Spain, in 2005 and 2012, respectively.

In 2000, he joined the faculty of UPC as an Assistant Professor with the Department of Electronics Engineering. His main research interest is the electromagnetic compatibility in power converters.

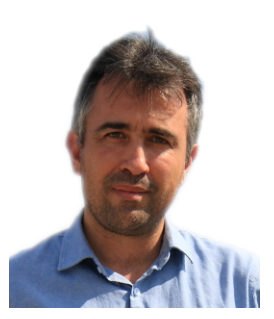

Eduardo Gálvez was born in Sevilla, Spain. $\mathrm{He}$ received the M.S. degree in telecomunications engineering from the Technical University of Valencia (UPV), Spain in 2000.

From 2000 to 2002, he worked as Probe Test Engineer at Analog Devices, Limerick, Ireland. From 2003 to 2005, he worked as electronic products Supplier Quality Engineer at Ficosa, Barcelona, Spain. Since 2005, he has been with Circutor, Viladecavalls, Spain, first as Development Engineer at Zurc development center. From 2010 to 2015 as Engineering Manager of Zurc, and since 2014 as Power Electronics Engineering Manager at Circutor development center. He has been granted 2 patents. Products designed by his development team have received several international awards.

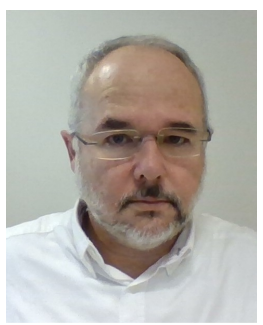

Alfonso Collado received the B.S. degree in electronics engineering from the Technical University of Catalonia (UPC), Barcelona, Spain, in 1989.

From 1986 to 1989, he was a Research Technician in Instrumentacion Industrial ZURC, Viladecavalls, Spain, becoming Technical Manager from 1989 until 2010. Since 2010, he is the R\&D\&i Manager in Circutor, Viladecavalls, Spain. During the last 3 years he has been working specially in innovative technologies and how to apply these to the new products developed by the company. His main research interests include, energy efficiency, power conversion efficiency, renewable energy, electric vehicles, and the new IoT opportunities to improve the consumer's behaviour about how to be more efficiency managing his consumptions. 